\title{
KU Leuven Open Science Day
}

\section{Open Science at KU Leuven}

\section{Sara Decoster ${ }^{1}$}

${ }^{\mathbf{1}_{K U}}$ Leuven

Published on: Jul 27, 2021

License: Creative Commons Attribution 4.0 International License (CC-BY 4.0). 


\section{Poster}

\section{KU LEUVEN}

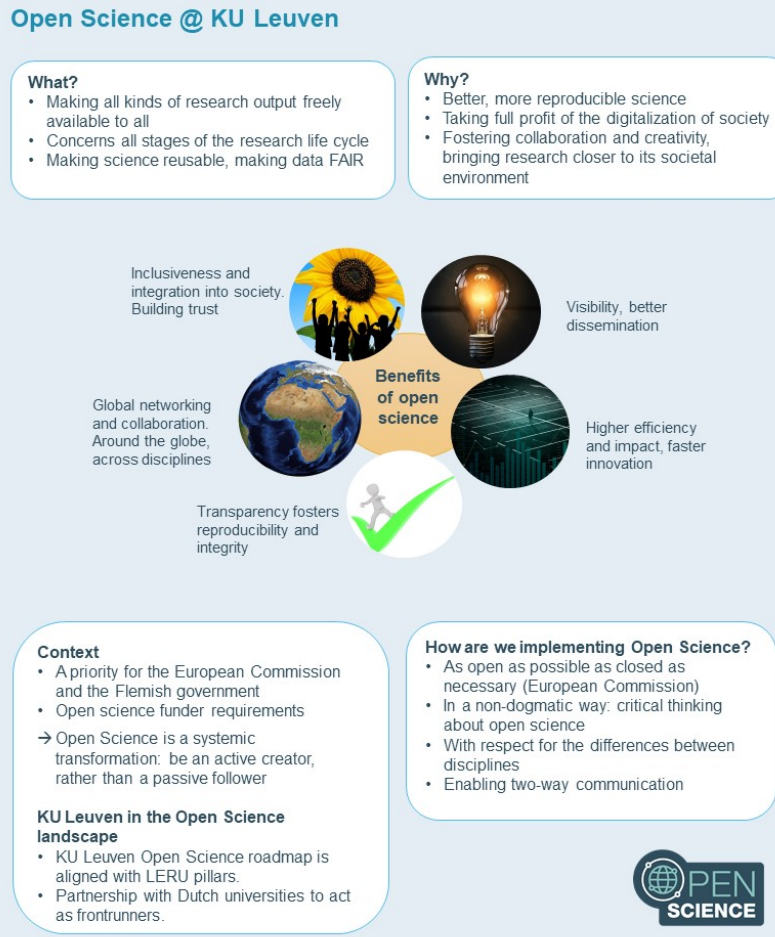

How are we implementing Open Science? - As open as possible as closed as In a non-dogmatic way critical thinking about open science With respect for the differences between disciplines

Enabling two-way communication

\section{Author biography}

Sara Decoster (KU Leuven) obtained a PhD in Languages and Letters at Liège University and works as an Open Science staff member at KU Leuven Libraries. She joined KU Leuven in 2018, as a metadata librarian for research data management. Previously, she held a position of library manager and research librarian at Liège University for eleven years. She gained international experience through participating in a development cooperation project and a two years' experience at Academia Belgica in Rome. 